\title{
A Research on Teaching Strategies to Cultivate the Critical Thinking Abilities of College Students in English learning
}

\author{
Zhang Lei ${ }^{1}$ \\ ${ }^{I}$ School of Foreign Language Studies, Dalian Jiaotong University, Dalian, Liaoning, China \\ *eiiris@163.com

\begin{abstract}
To cultivate college students' critical mind in learning English is one of the major objectives of College Education in China. The college English teaching cannot detain on the skill-training both in in-class teaching and autonomous learning process, but to promote the critical thinking abilities for students to achieve the function of tool-using and humane awareness, in order to help students to become well-rounded talents.
\end{abstract}

Keywords: critical thinking, English teaching, talents cultivation

\section{大学生英语创新能力的内涵式培养策略研究}

\author{
张蕾 ${ }^{1}$
}

${ }^{1}$ 大连交通大学外国语学院, 大连, 辽宁, 中国

*eiiris@163.com

\section{摘要}

促进大学生思辨能力的发展是我国高等教育的核心目标之一。大学英语课堂教学及课后自主学习不能仅仅停 留在语言技能的训练上, 而是要在教与学的双向沟通过程中引导学生全方位思考, 强化人文知识渗透, 培养学 生的思辨能力, 使英语习得能力的提升按照工具性与人文性并重的内涵式发展思路进行, 以适应 “全人” 教育 背景下人才综合素质提高的要求。

关键词: 思辨能力, 英语教学, 能力培养

\section{1. 引言}

促进大学生思辨能力的发展是我国高等教育的 核心目标之一。2010 年 7 月《国家中长期教育改革和 发展规划纲要 2010-2020 年》明确提出, 倡导启发式、 探究式、讨论式、参与式教学, 帮助学生学会学习, 营造独立思考、自由探索、勇于创新的良好环境。由 此可见, 培养和发展学生的思辨能力不仅是教育工作 者义不容辞的责任, 也是国家长期发展的战略任务。 无独有偶, 早在 20 世纪 40 年代中期, 世界著名学府 哈佛大学曾发布《自由社会的通识教育报告》中也明 确指出: 人才培养应具备以下四项重要的能力: 即有 效的思考能力, 清晰沟通思想的能力, 做出明确判断 的能力和辨识普遍性价值的认知能力, 一言以蔽之就 是思辨能力。冊庸置疑, 改革开放以来, 我国学生的
整体英语水平明显提高, 但凸显出来的问题就是这种 提高基本上停留在应试层面。背单词、答题、得高分 成了中国式英语学习的一贯做法。中国学生学习外语 所花的时间和精力堪称世界之最, 然而令人滥尥的却 是, 花费巨大精力, 学了十几年英语之后依然是 “张 不开口、写不出手”, 英语输出技能的欠缺仍旧制约 着学生们的英语实际应用。调查表明, 内地多数高校 学生对大学英语课程普遍感到授课质量不足, 要求提 升英语能力的愿望却非常强烈。大学生在学习英语时 采取的方式也多种多样, 各有不同。总体来讲, 优秀 学生主要依靠自我激励来学习, 通过看原版剧集、阅 读原版英文小说、浏览国外英文网站等方式满足自己 的学习需要, 这些学生对教师的依赖性相对较弱。但 对于普通学生来讲, 教师如果不想办法改善课堂效果, 学生学习动力就可能不足, 甚至产生挫败感。因此, 
大学英语实践教学不能仅停留在英语技能训练上, 而 要在教学过程中引导学生多思考, 加强人文知识渗透, 培养学生的思辨能力, 使英语习得按照工具性与人文 性并重的内涵式发展思路进行, 真正做到学以致用。

传统的大学英语课堂教学和指导学生课后自主 学习都专注于学生基本语言技能的训练, 布置大量语 法练习、词汇搭配或口语对话, 旨在提升大学生英语 语言使用的熟练程度, 保证语音语调清晰起伏, 确实 在很长时间里培养出了一大批语言流畅、语法合规的 英语使用者; 然而其弊端也日益凸显, 即 “学生在分 析、推理、评价、综合、辨析等方面的思辨能力表现 却不尽如人意” [1]。近年来, 中国外语界也日趋关注 大学生思辨能力提升过程中存在的问题和培养策略 研究。时代发展要求大学英语课堂及课后实践教学以 及自主学习过程中必须克服“思辨缺席症”[2], 从培养 流利的英语语言使用者到打造深度的英语思维思考 者, 在大学生思辨能力的培养方面着力实现质的突破。

与此同时, 理论研究者和一线教学的老师们也愈 加关注大学生思辨能力的理论与实践研究，成果颇丰。 在理论研究方面, 殷晓芳提出文本思辨创新式阅读教 学模式, 顺应了大学英语教学从技能型向思辨型转变 的形势要求。李莉文分析了英语专业技能课程与批判 性思维能力培养的关系问题, 探讨了以批判性思维能 力培养为导向的英语专业写作评测模式。孙有中认为 要使英语专业摆脱目前在大学学科体系中的弱势地 位, 必须以培养学生的思维能力为导向, 全面推进培 养目标、培养模式、课程设置、教学方法、测试方法、 教材编写和师资发展等方面的改革。在实证和实践研 究方面, 高一虹、文秋芳、刘润清等分别从演讲、口 语和写作等诸方面揭示了英语专业学生思维水平低 下的事实。文秋芳等构建了大学生思维能力测量量具。 刘晓民首次较为系统地提出了大学英语教学思辨能 力培养的模式构建, 马爽探讨了中国式英语学习的方 面趋势及对策, 阐述了英语思辨教育在人才培养中的 创新作用等。通过梳理归纳上述相关文献, 本课题组 成员发现, 当前国内思辨能力研究主要具有两个特点: 首先, 相关研究大都是围绕英语专业学生展开, 针对 非英语专业大学生的思辨教育研究成果较少, 普及程 度尚待提升; 其次可直接应用于二语习得教学实践 的思辨能力研究成果鲜见。多数研究都只是揭示了 “存在什么问题”, 对 “怎么解决问题” 探讨不足, 具 有可操作性的大学英语教学思辨能力培养模式也就 踪影难受。思辨能力培养可以纠正学生消极、守旧、 低效等不良思维习惯, 使他们掌握批判性地阅读、聆 听、观察、辩论和写作的能力, 从而提高其英语综合 应用能力。因此, 本文意在探索培养非英语专业大学 生英语实践能力的工具性和思辨能力的人文性两者 有机结合, 促进大学生群体的英语学习真正做到学以 致用, 提升 “全人” 复合能力, 以适应社会发展和国 际交流的需要。

\section{2. 英语实践能力的工具性培养策略}

在全球化的背景下，在英语同世界交往、吸收和 交流科技文化成果中起到越来越重要作用的时代, 大 学英语教学应该首先鲜明地提出工具性目标, 以适应 我国社会发展和国际交流的需要。大连交通大学大学 生创新英语竞赛工作室从项目筹备伊始, 团队教师就 秉持该理念, 据此指导学生的英语学习, 并不断在课 堂教学和课后学生自主学习的指导中加以实践。

首先，在授课内容上进行大刀阔斧的革新，精挑 细选授课语篇, 引入以学科内容为依托的语言教学、 学习及反思模式。这种全新并实用的模式旨在将诸如 文学、历史、科学及艺术等学科内容和英语语言的实 际应用有机结合, 使学生在学习该学科内容的同时, 提高自己的批判性思维能力和语言水平[3] 。在教学 过程中, 教师首先带领学生了解学科内容常用英语表 达, 读懂文本语篇的基本含义, 再通过设计各种诸如 针对某一主题的资料搜集、对有争议并无明确结论热 点话题的整理等有认知难度的教学活动拓展学生思 维, 鼓励学生进行搜集资料, 研读资料, 撰写调查报 告等拓展思辨能力发展的各类有效学习活动。此外, 引导学生在面对各种与学习内容相关的材料时, 不能 仅仅凭借单纯机械性地记忆、储存和吸收, 还必须将 自己已有知识与现存材料进行关联分析、综合整理、 有效评价之后形成自己的观点, 从而掌握批判性思维 技能[4]。之所以选择以学科内容为依托的语言教学模 式, 就是更注重有意义的学习, 注重探索发现, 注重 思维提升, 而不只是注重语言的浅层学习, 在整个教 与学的过程中伴有各种需要学生思考的教学活动, 如 描述、排序、分类、比较、选择、依据原则解决问题 以及对信息进行评价等 [5]。通过一年来创新教学团 队对我校非英语专业 $\mathrm{A}$ 级精英层次班级学生进行的 内容依托式授课试点课堂的实践, 发现以学科内容为 依托的语言学习模式由于采用有相对认知高度和难 度的学科英语材料和相关学习任务的布置实施, 切实 促进了学生更高层次思维能力的发展。比如, 在学习 科技英语翻译课程时, 学生首先需要查找、搜集和汇 总科技前沿领域的新事物和新现象等文章, 结合教材 中指定单元所教授的翻译的方法和策略, 将科技文献 有效地进行英汉互译。得益于此前科技类中文资料的 学习整理, 学生能快速学以致用, 将科技前沿信息用 英文完整流畅地翻译成文, 并储备于头脑中, 积累成 为英文写作、演讲甚至英语辩论的素材。

其次, 在实践教学环节, 增设英文演讲和辩论课 堂, 强化语言应用能力, 提升学生解决实际问题的能 力, 真正做到学以致用。早在古希腊时代, 演讲和辩 论即成为西方教育的重要组成部分。在我国, 先秦时 期的中国学者们也开启了演说和辩论的传统, “羽 扇纶中, 谈笑间, 樯橹灰飞烟灭” 生动形象地说明演 说和辩论的重要作用, 并有很强的实用性。大到国家 命运, 小到个人前途, 演讲和辩论的能力均能辅助事 业顺利和个人幸福。英语学习的终极目标就是应用, 流利地使用英语表达个人思想, 传播中华文化理念, 
讲好中国故事更应该成为所有非英语专业大学生的 学习目标。如何提升学生英语水平, 公共英语演讲和 辩论都不失为大学英语课堂上一种极好的教育手段, 同时对听说读写译等综合能力的全面提升也收效显 著。

\section{1. 阅读量和词汇量}

英语演讲和辩论的话题五花八门, 创新团队的教 师为学生们选用最新版的权威教材, 如《大学生英语 辩论入门》, 《赢在辩论》, 《演讲的艺术》等帮助学生 系统训练英文演讲和辩论的方法, 下载分发涉及各行 各业的专业文献, 比如一篇中国旗袍为话题的演讲稿, 其目的是让听众了解中国旗袍的起源、款式以及文化 影响, 这一题材的汉语资料汗牛充栋, 但英语文献却 并不充分。学生们借此机会学习英文表达中华文化的 词汇, 为讲好中国故事打好基础。同时, 学习的内容 也可以延展到教材之外, 学习了解国际国内的政治、 经济、文化、教育等方方面面。团队教师根据单元主 题提前布置讨论话题, 学生们在准备过程中, 需要查 阅大量文献资料，使用精读和泛读相结合的阅读方式， 在认知基础上理解，进而归纳总结并形成自己的观点。 这种有别于老师要求学生背单词的主动学习, 使单词 记忆更扎实、使用更灵活。能经常地有目的性地选择 阅读英文书籍和报刊杂志, 用以激发灵感, 积累素材, 扩充词汇, 才能保持与时俱进的精神。

同时, 英语演讲要求力度和效果, 经常训练可以 使学生提升语言的驾驭能力, 增强语言表达的准确性 和生动性。学生们普遍会达到扩大词汇量, 并掌握 词语的内涵和外延, 还能学会识别和删除赘词, 提升 演讲的感染力。

\section{2. 听力和口语}

听力是指听懂别人说话的能力。自己流畅表达与 听懂对方是社会言语交流中密不可分的有机组成部 分。如果将说话理解为言语生成和言语信息编码的过 程, 那么听话毫无疑问是言语信息的有效解码过程。 两个过程有机结合, 完成信息传递与言语交流的任务, 达成社交目的。因此, 如这两大能力中任何一种有所 欠缺,都会极大妨碍言语交流, 影响信息沟通。课堂英 语演讲活动不仅是对走上讲台发声学生的口语训练, 更是对座下听众学生的有效听力训练。演讲以讲为主, 以演为辅, 二者有效结合达到提供信息、以情动人、 以理服人的目的。

演讲过程对学生的听力注意力、听力辨析力和听 力理解力都是非常有效的训练。首先, 学生们在听演 讲者发言时要聚精会神,全神贯注,有效分配注意力, 同步完成分层次记观点, 追踪思维走向, 得出最后结 论等听力任务。在英语演讲中, 学生站在讲台上没有 任何文稿提示, 语言潜力得到最大限度的激发, 在英 语即兴演讲和即兴问答时, 大脑转速飞快, 一旦有了 思路, 大脑就会给发声器官传达信号, 因此学生的口
语会有意想不到的进步。整个学习状态都是积极的、 良性的。

课堂上的英语小组辩论更是学生参与热情极高 的重要环节。每位辩手要迅速摸清对方陈述时的语气、 语调, 品味出其情感、目的和意图, 准确判断其内容正 误和 是非曲直。这种对听话辨析力的高强度训练, 保 证学生们日后听课、参加会议、听取工作布置、参加 社会活动或实施工程计划都能思路清晰, 提升效率。

\section{3. 写作}

攥写英语演讲稿和准备辩论辩词是成功组织演 讲和辩论的关键环节，同时也对作为二语习得的中国 大学生来说是个不小的挑战。由于演讲和辩论话题涉 及方方面面, 学生们了解问题、看待问题的角度和维 度随之拓宽, 知识构成框架也日渐复杂, 写作的思路 会更加清晰, 观点的提炼、理论的框架也会变得逻辑 分明。由于在演讲和辩论实践中学会了论证过程, 学 生的讲稿不再是空喊的口号或自以为是的观点, 而进 阶成为有理有据的推理过程, 写作中的词汇、句型也 不再单一。

\section{3. 英语思辨能力的人文性内涵发展}

在强调语言学习工具性的同时, 学生思维成长过 程中的世界观、人生观、价值观、中国情怀，国际视 野与合作精神更是今后他们能踏实工作, 努力向上, 成为国际型人才不可或缺的内涵特点。针对这种长期 复杂的思维提升要求, 课题组教师团队将训练项目更 加具体化并提供一切可能的创新竞赛平台, 为优秀学 生脱颖而出创造条件。

\section{1. 成立创新英语工作室，建立竞赛团队， 开展校园英语活动}

以培养创新精神和实践能力为重点的素质教育 是当今高等教育改革的主旋律, 我校外国语学院大学 生创新英语工作室可以成为培养大学生思辨创新能 力和英语综合运用能力的有效途径及课堂英语教学 的有益补充。工作室开展的校园文化活动以素质教育 为理念, 为青年大学生提供平台及契机交流观点, 切 磋特长, 合作共赢。充分重视学生在英语活动中主 体地位的同时, 宏观把控校园英语活动的品质, 以配 音大赛锻炼学生的模仿能力, 以演讲大赛提升学生的 公众演说效力, 以辩论大赛训练学生的批判性思维, 以阅读和写作大赛传达国际重大时事和世界文明, 以 拓展学生国际视野, 提升解决问题的能力, 真正做到 学以致用。著名的心理学家布鲁纳指出: “知识的获得 是一个主动的过程, 学习者不应是信息的被动接受 者。” 策划筹备比赛, 赛事组织, 管理协调等事务让 学生懂得理解合作, 高效工作, 团队打造等社会实践 能力的重要性, 为提升其综合素质和文化内涵打下坚 实的基础。 


\section{2. 选派优秀学员参加国内各级各类英语竞 赛，提升英语实践内涵，拓展视野，打造国 际型人才}

极具影响力的国家级大学英语教学指导委员会, 共青团中央学校部及国内顶级大学和权威出版社每 年都会开展旨在培养和选拔高端人才, 提升高端人才 外语能力、思辨能力、交际能力、创新能力的各级各 类英语竞赛, 赛题多以国际化人才培养目标为标准, 综合融入思辨性、拓展性和创造性等关键要素, 以期 增强学生的跨文化交际意识, 开拓学生们的国际视野, 提升国际素养和内涵。英语竞赛的过程本身就是课堂 教学的延续, 给学生创造机会深入思考各种重大国际 问题, 提高学生思辨能力, 分析能力, 理解全局观念 的重要性, 以主动培养和提升自身的团队合作精神。 通过了解和参与国家、辽宁省以及大连市等各层面的 英语竞赛, 学生们可以为毕业后的职场奔波添加竞赛 资本, 书写光鲜履历。在比赛中, 学生暴露出的缺少 独立思维, 知识面狭窄等弊端, 学习视野仅仅局限于 本专业有关, 对其他社会、历史、文化等方面涉猎不 够, 在应试教育体系下缺少的独立自主思考的能力, 散发性思维和逆向思维得不到有效发挥等问题, 无一 例外地指向思辨能力不足，无法灵活运用知识的问题。 同时, 参加国家级大赛能极大的提升心理素质。大学 生英语演讲大赛, 辩论大赛对学生短时间的知识爆发 能力要求极高, 很多同学本来英语功底尚可, 但因为 信心不足, 参赛经验尚浅, 从开始的对自己的能力肯 定, 慢慢地对自己开始怀疑, 到最后甚至有些学生产 生了放弃英语比赛的念头, 这些都应得到指导教师的 重视, 合理地进行引导, 提升其自信心, 以期未来适 应更加复杂的社会和职场生活。

\section{4. 结论}

大学英语思辨教学任重道远。高校教师, 尤其是 创新团队指导教师在今后的实践教学和学生活动中, 也应以学生思辨能力的“工具”实用性和“人文”通用 性并重的理念为指导, 搭建二语习得能力内涵式发展 的理论框架, 以期提升“全人”教育背景下大学生的综 合素质。在理论上, 本研究从课堂及课后的思辨教 学入手, 按照 “工具性” 和 “人文性” 并重的指导思 想, 构建二语习得能力内涵式发展的理论框架, 运用 上述双标准查看思辨教学实践对学生英语能力提高 的影响, 可以总结提炼出 “全人” 教育背景下人才培 养的新模式。在实践中, 本研究更好地把握创新环境 下教师教学和学生学习的影响方式、影响内容以及存 在的问题, 对二语习得过程及能力的发展进行全面的 把握和提供对策建议。同时, 带领学生参加各级各类 英语竞赛, 为优秀学员脱颖而出创造条件, 运用创新 模式培养杰出人才, 增强我校在辽宁省内外乃至国内 外的影响力。

\section{项目基金}

本文为大连交通大学校级教改项目《大学生英语 创新工作室运行模式的探究与实践》(项目编号: DJDJG201549) 的研究成果之一。

\section{REFERENCES}

[1] Liu, X, M. (2013) On Cultivating Critical Thinking in College English Teaching. J. Foreign Language World, (5): 59-66.

[2] Huang,Y,S. (2010) On the Absence of Critical Thinking. J. Foreign Language World, (1) : 11-16.

[3] Kasper, L. F. (2000) New technologies, new literacies: Focus discipline research and ESL learning communities. J. Language Learning \& Technology, (2) : 105-128.

[4] Bloom, B. S. (1956) Taxonomy of Educational Objectives: The Classification of Educational Goals . Handbook 1: The Cognitive Domain. New York: Longmans, Green \& Co.

[5] Mohan, B. A. Integration of language and content. (1990) In: Proceedings of the First Research Symposium on Limited English Proficient Students' Issues Washington D. C: Office of Bilingual Education and Minority Language Affairs, : 113160. 